\title{
Stability Theory of Elastic Rods
}

E气

害

. 


\title{
SERIES ON STABILITY, VIBRATION AND CONTROL OF SYSTEMS
}

\section{Series Editors: Ardéshir Guran \& Daniel J. Inman}

\begin{abstract}
About the Series
Rapid developments in system dynamics and control, areas related to many other topics in applied mathematics, call for comprehensive presentations of current topics. This series contains textbooks, monographs, treatises, conference proceedings and a collection of thematically organized research or pedagogical articles addressing dynamical systems and control.

The material is ideal for a general scientific and engineering readership, and is also mathematically precise enough to be a useful reference for research specialists in mechanics and control, nonlinear dynamics, and in applied mathematics and physics.
\end{abstract}

\section{Selected Forthcoming Volumes}

Series A. Textbooks, Monographs and Treatises

Stability Theory of Elastic Rods

\section{Author: T. Atanackovic}

Dynamics of Gyroscopic Systems: Flow Induced Vibration of Structures, Gyroelasticity, Oscillation of Rotors and Mechanics of High Speed Axially Moving Material Systems

Authors: A. Guran, A. Bajaj, G. D'Eleuterio, N. Perkins and Y. Ishida

Adaptive Control of Nonlinear Systems

Authors: R. Ghanadan, A. Guran and G. Blankenship

Series B. Conference Proceedings and Special Theme Issues

Wave Motion, Intelligent Structures and Nonlinear Mechanics

Editors: A. Guran and D. J. Inman

Acoustic Interactions with Submerged Elastic Structures

Part I: Acoustic Scattering and Resonances

Editors: A. Guran, J. Ripoche and F. Ziegler

Part II: Propagation, Ocean Acoustics and Scattering

Editors: A. Guran, G. Maugin and J. Engelbrecht

Part III: Acoustic Propagation and Scattering. Wavelets and

Time-Frequency Analysis

Editors: A. Guran, A. de Hoop and D. Guicking

Part IV: Non-destructive Testing. Acoustic Wave Propagation and Scattering

Editors: A. Guran, A. Boström, A. Gerard and G. Maze

Structronic Systems: Active Structures, Devices, and Systems

Editors: H.-S. Tzou, A. Guran, G. A deson D. J. Inman and M. C. Natori 
SERIES ON STABILITY, VIBRATION AND CONTROL OF SYSTEMS Series A

Volume 1

Series Editors: Ardéshir Guran \& Daniel J Inman

\section{Stability Theory of Elastic Rods}

\section{Teodor M. Atanackovic}




\section{Published by}

World Scientific Publishing Co. Pte, Lid.

P O Box 128, Farrer Road, Singapore 912805

USA office: Suite 1B, 1060 Main Street, River Edge, NJ 07661

UK office: 57 Shelton Street, Covent Garden, London WC2H 9HE

\section{British Library Cataloguing-in-Publication Data}

A catalogue record for this book is available from the British Library

\section{STABILITY THEORY OF ELASTIC RODS}

Copynght (c) 1997 by World Scientific Publishing Co. Pte. Lid

All rights reserved. This book, or parts thereof, may not be reproduced in any form or by any means. electronic or mechanical, including photocopying, recording or any information storage und retrieval system now known or to be invented, withouf wrilten permission from the Publisher.

For photocopying of material in this volume, please pay a copying fee through the Copyright Clearance Center, Inc., 222 Rosewood Drive, Danvers, MA 01923, USA. In this case permission to photocopy is not required from the publisher

ISBN 981-02-3054-0

This book is pnnted on acid-free paper 


\title{
STABILITY, VIBRATION \\ AND \\ CONTROL OF SYSTEMS
}

\author{
Editor-in-chief Ardéshir Guran \\ Con-editor: \\ Damel J. Inman
}

Henry Abarbanel

Inversity of Califorma

San Dirko

USA

Gary Anderson

Army Research Office

Revearch Iriangie Park

USA

Jorge Angeles

McGill University

Montrèal

CANADA

Leon Bahar

Drexel University

Philadelphia

USA

Anil Bajaj

Purdue University

Lafayette

UISA

Anders Bostrōm

Chatmen Technucal tiniv

Gutebork

SWEDEN

Rafael Carbo-Fite

CSIC

Madnd

SPAIN

Fabio Cusciati

Unuversitá di Pavas

Pavia

ITALY

Juri Eugelbrecht

Fstonian Acartemy of Sci

Tallin

ESTONIA

\section{Lucia Faravelli \\ Universila di Pavia \\ Pavia}

ITALY

\section{Advisory Board}

Toshio Fukuda

Nagoya Unversity

Nagoya

JAPAN

Alain Gerard

Laboratoure de Mécanique

Bordeaux

ERANCE

Hans Irschik

Jahannes Kepler linuversitat

Lins

ALSTHIA

Meikki Isomãki

Helsinki Unu of Tech.

Helsinks

FINLAND

\section{Jer-ban Juang}

Langley Renearch Center

Hampton

USA

John Junkins

Texas ANM University

College Station

USA

Youdan Kim

Seoul National University

Scoul

KORF.A

\section{James Knowles}

California last of Tedi

Pasadena

USA

Edwin Kreuzer

Techuasche Universital.

Hamburg. Harburg

GERMANY

\section{Oswald Leroy \\ Catholic University of \\ Louvan.}

BEI.GIUM
Jerrold Marsden

Califorma linst of Terh

Pasadena

ISA

Hans Natke

Universilat Hannoves

Hannover

GERMANY

\section{Paul Newton}

Eniversity of \$ Californas

Los Angeles

USA

\section{Michihiro Natori}

Lnat. of Space \& Astro

Kanagwa

JAPAN

Friedrich Pfeiffer

Technische Universitat

Munchen

GERMANY

Raymond Plaut

Virgnia Poly thst

Blacksturk

USA

\section{Kart Popp}

Universitat Hannover

Hannever

GERMANY

Richard Rand

Comell University

Ithach

USA

Jean Ripoche

Unuversity of l.e Havre

Le Havte

FHANCF.

Kazimirez Sebczyk

Polish Academy of Sce

Warsaw

POLAND
Jon Juel Thomsen

Tech. Univ of Denmark

Lyngby

DENMARK

\section{Horn-Sen Tron}

Univenity of Kentucky

Lexington

USA

Herbert Û̉beral!

Gathole line of America Washington

I.SA

Firdaus Udwadia

University of S Californa

tos Angeles

USA

Dick van Campen

IInversity of Technology

Eindhoven

NFTHERLANDS

\section{Jĩrg Wauer}

Techusche Unversitat Karlsruhe

GEHMANY

Joanne Wegner

Unversily of Victoria

Victoria

CANADA

James Yas

Treas A\&M University

College Station

ISA

Lotfi Zadeh

Eniversity of Caluforma

Berkeley

USA

Franz Ziegler

Techrische Onuvenitiat

Wien

AUSIRIA 
This page is intentionally left blank

: 


\section{Preface}

This book is an extended version of my book Stability theory of elastic rods, written in Serbian, and published by Faculty of Technical Sciences in Novi Sad 1987. It grew out of the lectures that I was giving to the fourth year engineering students, specializing in applied mechanics at the University of Novi Sad. It treats two specific parts of the stability theory of elastic bodies. First, it is concerned with the stability of equilibrium states and second, it treats elastic rods only. The mathematical methods presented here could, however, give an insight into the stability analysis of a given state, not necessarily equilibrium, of an elastic body to be investigated. For the case of relative equilibrium, that is, equilibrium with respect to a moving coordinate system the methods presented here, apply directly. Also stability analysis of elastic rods shows, in principle, how to proceed in the case of two-dimensional (plates and shells) and three-dimensional bodics. I hope that the present text will be read in conjunction with the classics in the filed such as: Timoshenko, S.P. and Gere, J.M. Theory of Elastic Stability, Volmir, A.S. Stability of Deformable Systems, Knops, R.J. and Wilkes, E.W. article Theory of Elastic Stability in Handbuch der Physik Via/3 and Leipholz, H. Stability of elastic Systems.

The book is addressed to senior undergraduate students with emphasis on mechanics and (or) applied mathematics and graduate engineering students. It is divided in five Chapters.

Chapter 1 is conceived as an introduction where general notions of rod, rod axis and rod cross-sections are presented. Also, we discuss possible rod models for stability analysis and give basic ideas about Euler, energy and dynamic method of stability analysis. The notions of structural stability and practical stability are introduced as well. 
Chapter 2 deals with basic equations of the elastic rod theory. Plane deformations are considered first. The classic Bernoulli-Euler model follows as a special case of various gencralized models. Special attention is given to models that take shear stress effects into account and to classification of such models. We distinguish three approaches: Engesser's, Haringx's and Timoshenko's. In treating spatial deformations of elastic rods three different choices of Euler type angles describing orientation of a cross-section with respect to a fixed Cartesian coordinate system are introduced. This chapter also gives solution of equilibrium equations for certain types of loads and boundary conditions. Among the classic solutions, we analyze an inverse problem (the shape of the piston ring) and a curiosity called negativism. An important characteristics of this Chapter is that only linear (in selected strain measures) constitutive equations are used.

Chapter 3 begins with stability analysis. First the Euler method of adjacent equilibrium configuration is treated. It is shown that the question of instability or stability of a certain equilibrium configuration is mathematically reduced to the problem of determining whether certain non-linear operator does or does not have a bifurcation point. The Liapunov-Schmidt reduction is described as one possible method of determining bifurcation point. The method is illustrated by several examples. Some are classic ones and some are newer. In presenting the classic examples, we tried to include various generalizations and extensions that appear in literature. This is specially true for Sections 3.3, 3.10, 3.13, 3.18 and 3.19.

Chapter 4 deals with the energy method for stability analysis. The energy method is taken as an independent method of stability analysis and its relation to Euler method is examined. Then, a procedure is formulated to determine stability boundary according to the energy method. This procedure is fully escorted on a model example in Section 4.2. Later in Chapter 4 a selected number of examples is treated. Some of these examples were previously treated by Euler method in Chapter 3. In Section 4.9 several variation principles and a priori estimates of maximal deflection are presented. It is shown then how those estimates could be used to estimate the critical load for the case of rods with variable cross-sections.

Chapter 5 contains the dynamic method of stability analysis. Both first and second Liapunov method are presented together with Liapunov stability theorems. Connection with the energy method is discussed. The method is then applied to several examples. This chapter also contains generaliza- 
tion of some classic results. For example, the influence of shear, compressibility and pulsating force is examined on the case of Beck's and Pflüger's rods. This Chapter closes with the generalization of minimal length necessary for buckling formula obtained by the dynamic method,

The References, given at the end, are by no means completc. Instead, our intention was to cite only works that are relevant for the examples treated.

Finally, I would like to express my gratitude to Professors B.D. Vujanovic, University of Novi Sad and I Müller, Technische Universität Berlin for encouraging me to write this book. With my colleges B. Baclic, Dj.S. Djukic and L. Cveticanin I had numerous discussions about the content. Professor Baclic helped me to type, revicw and edit the manuscript. This help was essential. Professor A. Guran, University of Southern Califomia, helped me to improve the final version of the text and suggested extension of some sections. It is also my pleasure to acknowledge the financial support of Alexander von Humboldt-Stiftung of the Federal Republic of Germany. During my stay in Berlin, financed by Alexander von Humboldt-Stiftung, some parts of this book were written.

The help that I received from my daughters Jelena and Milica is hard to describe. But it was crucial. I therefore dedicate this book to them.

Novi Sad, 1996 
This page is intentionally left blank

: 


\section{Table of Contents}

Preface V

Chapter 1. Introduction

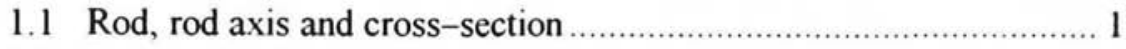

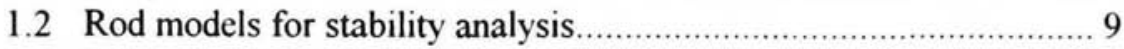

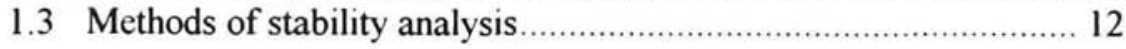

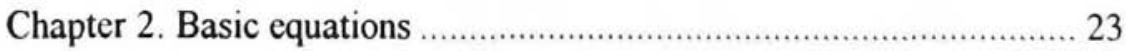

2.1 Basic equations for a plane deformation of an elastic rod ............... 23

2.2 Linearized equations of the plane elastic rods .............................. 36

2.3 The influence of shear stresses on the plane deformation................. 38

2.4 Basic equations for spatially deformed rods with inextensible axis . 49

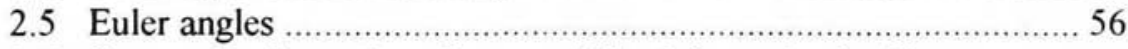

2.6 Summary of equations for a spatially deformed rod with

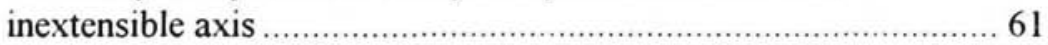

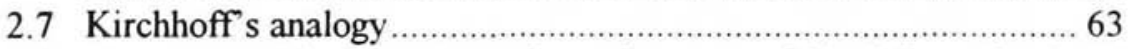

2.8 Concentrated forces and couples acting on spatially deformed rod. 65

2.9 Spatially deformed rod with extensibility and shear ...................... 67

2.10 Solutions of differential equations for some finitely deformed

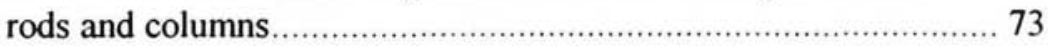

i) Centrally compressed column ................................................ 73

ii) Centrally compressed, simply supported compressible rod ........76

iii) Cantilever beam loaded by a concentrated force....................... 80

iv) axially loaded rod with a concentrated force in the middle........ 84

v) axially loaded rod with shear and compressibility ................... 88 
2.11 An inverse problem: the shape of a piston ring ...................... 89

2.12 Negativism .................................................................... 94

Chapter 3. The adjacent equilibrium method for stability analysis........ 99

3.1 The adjacent equilibrium method (Euler method) and its relation to bifurcation theory .............................................................. 99

3.2 Rod with a constant cross-section loaded at end points.

3.3 The influence of compressibility and shear on the stability bounds for the rod with the constant cross-section .............................120

3.4 Column loaded by two forces................................................. 132

3.5 Column with a step change in the cross-section.......................134

3.6 Column with a variable cross-section loaded by a concentrated force.

3.7 Rod on an elastic foundation ................................................. 140

3.8 Heavy vertical column ............................................................ 144

3.9 Heavy column with a variable cross-section.......................... 156

3.10 Buckling by extension.........................................................

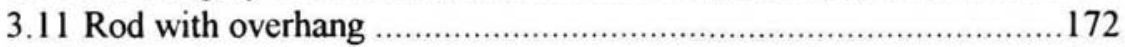

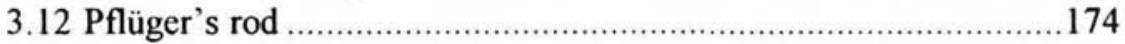

3.13 Heavy rod on a horizontal plane .......................................... 193

3.14 The strongest centrally compressed rod ....................................208

3.15 Heavy rotating column............................................................22

3.16 Circular ring loaded by uniform pressure .................................236

3.17 Rod loaded by a force and a couple ..........................................244

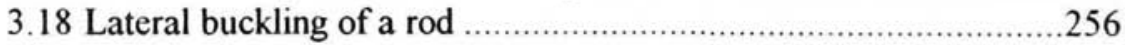

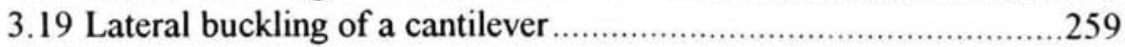

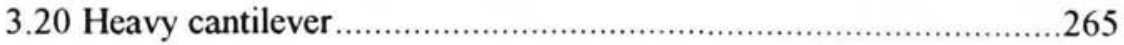

Chapter 4. The energy method for stability analysis .........................273

4.1 The energy method and its relation to Euler method ....................273

4.2 Column with a constant cross-section loaded at end point ...........281

4.3 Heavy compressible column with end force ...............................285

4.4 Rod with a constant cross-section loaded at end points ...............291

4.5 Heavy column with a shear compressibility and end force ...........296

4.6 Heavy rotating column with imperfections.................................300

4.7 Vertically positioned heavy rotating column ...............................309 
4.8 Use of canonical transformations .................................................

4.9 Various variational principles and a priori estimates.....................318

4.10 Rayleigh-Ritz and Galerkin methods for stability problems ….......326

Chapter 5 . The dynamic method of stability analysis ….....................335

5.I Equations for planar and spatial motion of a rod .........................335

5.2 Liapunov definitions of stability …….................................

5.3 Stability theorems

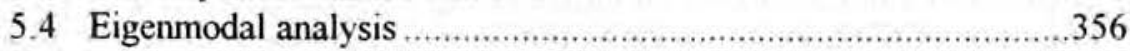

5.5 Simply supported, centrally compressed rod and heavy column ....359

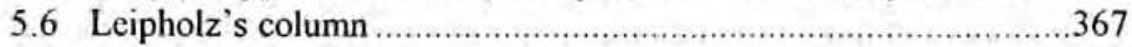

5.7 Beck's column

5.8 Uniformly accelerated rod under follower force ….......................380

5.9 Fluid conveying tube

5.10 Simply supported and Pflüger's rod with shear

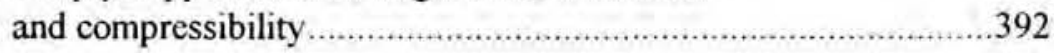

References

Index 